\title{
Review of injection therapy clinics performed by physiotherapists working in primary care
}

\section{Aims}

To determine painscores for injection therapy and to review the overall change in outcomes post injection for a variety of musculoskeletal injections compared with the previous audits of a NHS Primary care Physiotherapy injection clinic.

\section{Methods}

Five clinicians each kept a record of all patients they saw for injection therapy during October and November 2012.

When assessing painscales, patients were asked to verbally rate their pain between 0 and 10 , with 0 representing no pain and
10 representing very severe pain

After performing the injection an assessment sheet was completed. This was then passed to an Administrator in the Physiotherapy service who later telephoned patients for assessment of pain scores at 2 and 4 weeks post injection.

\section{Results}

A total of 141 injections were performed. 40 patients had incomplete data leaving a total of 101 injections which were analysed which had complete results at weeks 0,2 and 4 weeks post injection.

All average painscale scores are reduced 4 weeks after injection for all conditions.

There is an overall average reduction in pain on provoking activity of $45.7 \%(57.5 \%$ in $2010,54.7 \%$ in 2007 and $56.3 \%$ in 2004). When the 8 most commonly encountered conditions are analysed in the same manner the reduction is found to be:

- $56.3 \%$ for shoulder impingement syndrome (SIS) $(70.0 \%$ in $2010,58.4 \%$ in 2007 and $52.0 \%$ in 2004);

- $47.6 \%$ for shoulder capsulitis (33.7\% in 2010 , $31.5 \%$ in 2007 and $42.6 \%$ in 2004);

- $37.8 \%$ for knee joints (46.8\% in 2007);

- $36.9 \%$ for trochanteric bursitis $(44.4 \%$ in 2010 and $59.8 \%$ in 2007);

- $41.1 \%$ for plantar fasciitis (93.2\% in 2010);

- $65.0 \%$ for trigger finger/thumb (complete pain relief in 2010);

- $27.8 \%$ for tennis elbow $(60.2 \%$ in 2007 and 67.8 in 2004) and

- $44.4 \%$ for carpo-first metacarpal joints (no previous data available).

Where available, data for previous years is shown in brackets above.

Contrary to a common patient perception, injection therapy is not an exceptionally painful experience, with an average score of 3.2 (4.0 in 2010, 3.1 in 2007 and 3.8 in 2004).

\section{Conclusion}

- The injection clinics continue to be very successful, with good clinical outcomes at 4 weeks. Anecdotally they are appreciated and well supported by the primary care team and patients.

- Compared with 2010, painscores for the actual injection have fallen from 4.0 to 3.2 .

- The current results are comparable with previous reviews. Shoulder capsulitis and SIS continue to be the most commonly injected conditions.

- The most dramatic pain relief is found with injection of trigger finger/thumb as was the case in 2010

- It is recommended that the current injection clinics as described above are continued.

\begin{tabular}{|l|c|c|c|}
\hline Condition & $\begin{array}{c}\text { Total number } \\
\text { of injections }\end{array}$ & $\sim \%$ & $\begin{array}{c}\% \text { in } 2007 \\
\text { and } 2010\end{array}$ \\
\hline $\begin{array}{l}\text { Shoulder impingement syndrome } \\
\text { (SIS) }\end{array}$ & 21 & 21 & $30 \& 27$ \\
\hline Shoulder capsulitis & 18 & 18 & $23 \& 33$ \\
\hline Knee joint & 16 & 16 & $8.5 \& 0$ \\
\hline Plantar fasciitis & 10 & 10 & $2.4 \& 12$ \\
\hline Trochanteric bursitis & 10 & 10 & $7.3 \& 7$ \\
\hline Trigger finger/thumb & 9 & 9 & $3.7 \& 7$ \\
\hline Tennis elbow & 4 & 4 & $7.3 \& 5$ \\
\hline C-1st MC joint & 3 & 3 & $3.7 \& 5$ \\
\hline De Quervain's tenosynovitis & 2 & 2 & $3.7 \& 0$ \\
\hline Ischial bursitis & 2 & 2 & $0 \& 0$ \\
\hline Morton's neuroma & 2 & 2 & $0 \& 0$ \\
\hline Acromioclavicular joint (ACJ) & 1 & 1 & $1.2 \& 0$ \\
\hline Base of 2nd MT & 1 & 1 & $0 \& 0$ \\
\hline Golfer's elbow & 1 & 1 & $0 \& 2$ \\
\hline Wrist joint & 1 & 1 & $0 \& 0$ \\
\hline Total & 101 & 100 & \\
\hline
\end{tabular}

Combined data for all 101 injections (results from 2007 \& 2010 shown in brackets)

\begin{tabular}{|c|c|c|}
\hline $\begin{array}{c}\text { Average painscale on } \\
\text { provoking activity } \\
\text { pre-injection }\end{array}$ & $\begin{array}{c}\text { Average painscale for } \\
\text { injection }\end{array}$ & $\begin{array}{c}\text { Average painscale on } \\
\text { provoking activity four } \\
\text { weeks post injection }\end{array}$ \\
\hline $8.1(8.4 \& 8.7)$ & $3.2(3.1 \& 4.0)$ & $4.4(3.8 \& 3.7)$ \\
\hline $\begin{array}{c}\text { Range: } 2 \text { to } 10 \\
(3 \text { to } 10 \& 3 \text { to } 10)\end{array}$ & $\begin{array}{c}\text { Range: } 0 \text { to } 10 \\
(0 \text { to } 10 \& 0 \text { to } 10)\end{array}$ & $\begin{array}{c}\text { Range: } 0 \text { to } 10 \\
(0 \text { to } 10 \& 0 \text { to } 10)\end{array}$ \\
\hline
\end{tabular}

Average painscores pre-injection and 4 weeks post injection

\section{Painscale pre injection (blue line) and 4 weeks post injection (pink line)}

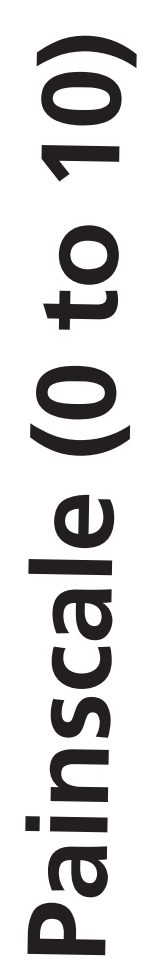

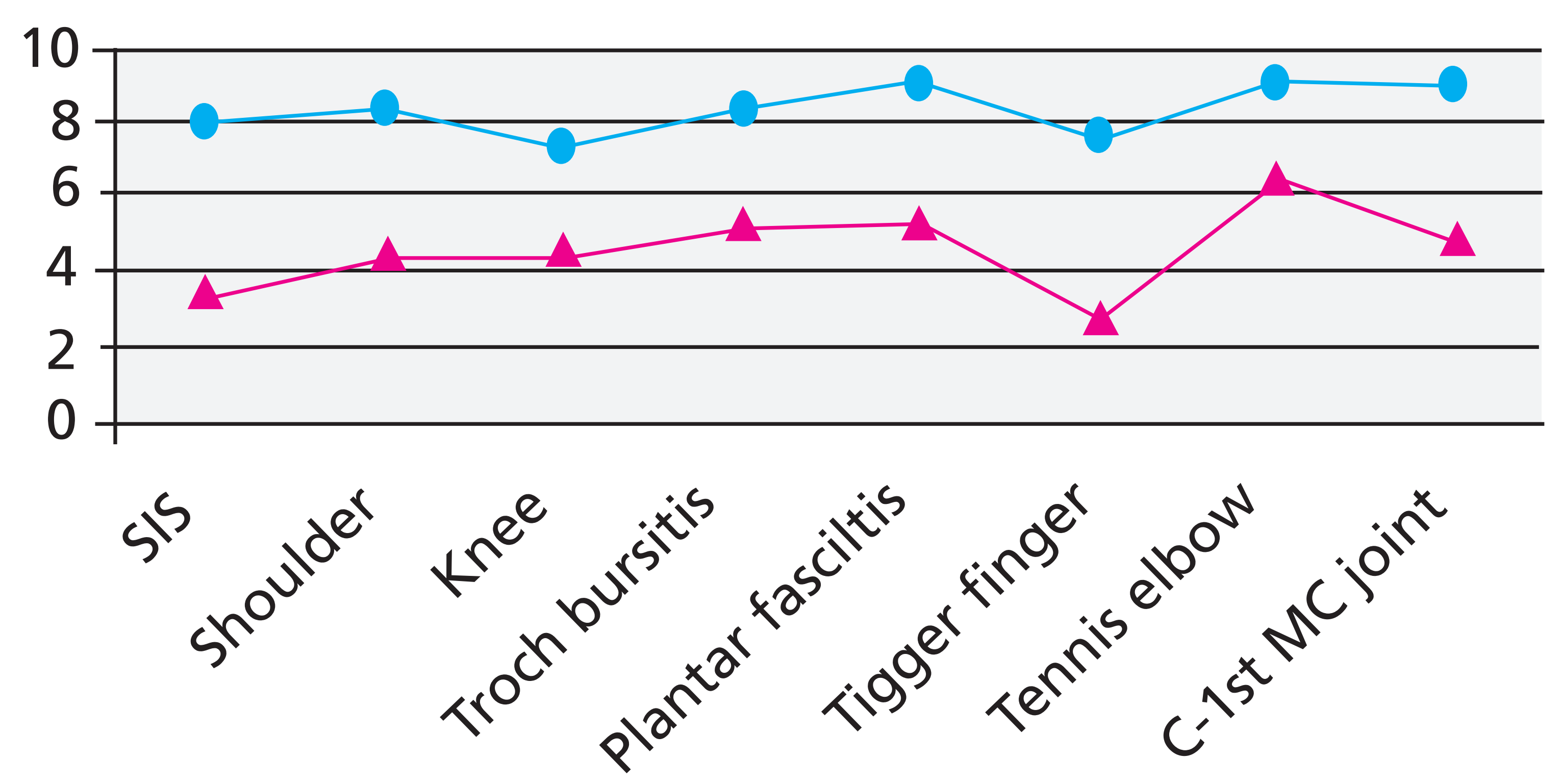

Condition 